\title{
Variations of chlorophyll-a and particulate organic carbon in the Yellow-Bohai Sea: in response to the Typhoon Lekima event
}

Xiaowen Wang ${ }^{1}$, Xiujun Wang ${ }^{1 *}\left(\mathbb{0}\right.$ and Zai-Jin You ${ }^{2,3}$

\begin{abstract}
Typhoon events have large impacts on marginal seas' environmental conditions with implications for biological processes and carbon cycling. However, little is known about the responses of phytoplankton and particulate organic carbon (POC) to typhoon events in the Yellow-Bohai Sea (YBS). In this study, we utilized satellite-derived datasets of chlorophyll-a (Chl-a) and POC, together with key physical parameters, to analyze their responses to the Typhoon Lekima event induced heavy rainfall and strong winds. Overall, there were enhanced upwelling, strengthened currents, and increased terrestrial runoff during weakened Typhoon Lekima in the YBS. The basin-scale response of Chl-a showed large differences post the Typhoon Lekima event, with a decrease in the Bohai Sea (BS, $0.34 \pm 3.0 \mathrm{mg} \mathrm{m}^{-3}$ ) but an increase in Yellow Sea (YS, $0.23 \pm 1.7 \mathrm{mg} \mathrm{m}^{-3}$ in the south YS and $0.54 \pm 0.8 \mathrm{mg} \mathrm{m}^{-3}$ in the north YS). The increase of Chl-a in the YS was attributed to increased nutrients, whereas the reduction of Chl-a in the BS was caused by dilution and water exchange with the North Yellow Sea. However, there was an overall increase in POC post-Typhoon Lekima in both BS and YS. The increase of POC in the majority of BS resulted largely from enhanced sediment resuspension and terrigenous input. The increase of POC in the nearshore waters of YS was attributable to enhanced biological production, sediment resuspension, and terrigenous input of POC, whereas the increase of POC in the central YS was partly due to transportation of high-POC waters from nearshore to offshore via strengthened current. Our study highlights the complex impacts of typhoon events on the carbon cycle in marginal seas.
\end{abstract}

Keywords: Chlorophyll-a, Particulate organic carbon, Typhoon Lekima, Remote sensing, Yellow-Bohai Sea

\section{Introduction}

Typhoons are one of the most intensive meteorological activities on earth and can impose significant impacts on the marine environment. Typhoon-induced strong wind can cause significant entrainment and upwelling in the ocean, which uplifts nutrient-rich subsurface water to the surface layer of water column (Liu et al. 2019; Pan et al. 2018). As a result, nutrient concentration in surface water often increases during/after the passage of typhoon, which stimulates phytoplankton growth and

\footnotetext{
*Correspondence: xwang@bnu.edu.cn

${ }^{1}$ College of Global Change and Earth System Science, Beijing Normal University, Beijing 100875, China

Full list of author information is available at the end of the article
}

thus enhances primary production (Chen et al. 2017). The extent and strength of biological responses are influenced by the intensity of typhoon and the changes in environmental conditions (Pan et al. 2017; Zhao et al. 2013).

There is evidence of high frequency of typhoon passages in marginal seas, and great impacts of typhooninduced strong wind on its biogeochemistry because of the marginal seas' shallow stratification that is easily broken (Chen et al. 2017). In addition to the enhanced nutrient supply from subsurface of the ocean, typhooninduced heavy rainfall could increase runoff, thus delivering more nutrients from adjacent lands (Shiah et al. 2000). Previous studies reported that marginal seas, occupying $7-10 \%$ area of the global ocean, contributed 
$\sim 30 \%$ of global ocean's primary productivity (Bauer et al. 2013; Fang et al. 2018). Thus, studying the impacts of typhoons on marginal seas' biogeochemical processes is important to our understanding of the carbon cycle at regional-to-global scales.

The response of phytoplankton to the passage of typhoons varies largely due to the differences in the characteristics of typhoons and the water column conditions, particularly in the marginal seas (Hernandez et al. 2020; Huang et al. 2011). On one hand, many studies reported phytoplankton bloom during/after the passage of typhoons, as indicated by a significant increase in chlorophyll-a (Chl-a) concentration (Hernandez et al. 2020; Liu et al. 2019; Ning et al. 2019). On the other hand, there was evidence of decrease (relative to prior-typhoon conditions) in phytoplankton biomass following typhoon events due to various mechanisms such as dilution, water exchange, and light limitation caused by enhanced resuspension (Huang et al. 2011; Hung et al. 2010; Wetz and Paerl 2008; Wiegner et al. 2012).

Extreme weather events can have large impacts on the dynamics of organic carbon in shallow waters. An analysis based on 20-year data collected in Neuse River Estuary (N Carolina, US) showed that total organic carbon often increased following hurricane events, which was due to enhanced primary production and also terrestrial input (Paerl et al. 2020). There was evidence of elevated particulate organic carbon (POC) in association with typhoon-induced phytoplankton blooms in reservoir (Gao et al. 2021) and shallow seawater (Chen and Tang 2011). Some studies also showed increased POC in coastal waters, which was associated with typhooninduced enhancements of various physical processes, including terrestrial runoff (Liu et al. 2007), sediment resuspension, and coastal upwelling (Shiah et al. 2000).

Mid-latitude marginal seas are experiencing increasing numbers of intensive typhoon events in recent years (Wang and Toumi 2021). However, there have been a handful of studies addressing the impacts of typhoon events particularly on biogeochemistry and carbon cycling in mid-latitude marginal seas (Son et al. 2006; Tsuchiya et al. 2017). The Yellow-Bohai Sea (YBS), a semi-enclosed shallow marginal sea, is largely influenced by terrestrial runoff and wind-stirring induced resuspension of sediments. There has been an increasing number of typhoon events over the past, with about two typhoon events each year during the recent decade in the YBS (http://agora.ex.nii.ac.jp/digital-typho on/). The Typhoon Lekima passed through the western YBS and adjacent lands in August 2019, having large impacts on the environmental conditions ( $\mathrm{Lu}$ et al. 2020), with implications for biogeochemical processes and the carbon cycle. Here, we analyze satellite-derived Chl-a, POC and other relevant data to investigate the impacts of the Typhoon Lekima event on key physical and biogeochemical fields in different sections of the YBS. The objectives of this study are: (1) to evaluate the responses of biogeochemical processes and carbon cycle to typhoon-induced changes in environmental conditions, and (2) to explore the potential mechanism regulating the variation of POC in the YBS. This work aims to better understand the responses of carbon cycle to environmental changes in marginal seas.

\section{Materials and methods}

\section{Descriptions of study area and Typhoon Lekima 2019}

The YBS, with an area of $\sim 4.6 \times 10^{5} \mathrm{~km}^{2}$, consists of three parts: Bohai Sea (BS), North Yellow Sea (NYS), and South Yellow Sea (SYS). Water depth in the YBS increases from north to south, with an average of about $18 \mathrm{~m}$ in BS, $38 \mathrm{~m}$ in NYS, and $46 \mathrm{~m}$ in SYS (Fig. 1). There is $\sim 7000 \mathrm{~km}$-long coastline with eight large rivers (defined as annual runoff $>5 \times 10^{9} \mathrm{~m}^{3}$ ) flowing into the YBS, transporting about $1.04 \times 10^{9} \mathrm{t}$ terrestrial materials into the YBS every year (according to Bulletin of China's River Sediment, http://www.mwr.gov.cn/sj/ tjgb/zghlnsgb/). The Yellow River deliveries $3.89 \times 10^{5} \mathrm{t}$ POC into the BS annually (Wang et al. 2012).

There is pronounced seasonality in the hydrological environment of the YBS. The main current system includes the northward Yellow Sea Warm Current (YSWC) and southward Yellow Sea Coastal Current (YSCC), which are strongest in winter and weakest in summer (Teague and Jacobs 2000). A bottom water mass, the Yellow Sea Cold Water Mass (YSCWM) in the centers of NYS and SYS, retains its winter characteristics in all seasons, causing remarkable vertical stratification in summer (Chen 2009; Xiu et al. 2009; Yang et al. 2014), which can be partly broken by stronger winds during typhoon events.

Typhoon Lekima generated on 4th August 2019, made landfall again in Zhejiang Province on 10th August, moved into the SYS on 11th August, and made landfall in Shandong Province on the same day. It then crossed Shandong Peninsula and moved into the BS at $\sim 5: 00$ on 12th August, and hovered over the BS, gradually dissipated until $\sim$ 14:00 on 13th August (Fig. 1). According to the Saffir-Simpson scale (Wang and Wang 2021), Typhoon Lekima was a Category 4 typhoon, but the intensity was depressed during the passage in the YBS, with the diameter of the typhon-induced gale ranging from 660 to $1400 \mathrm{~km}$ (http://agora.ex.nii.ac.jp/digitaltyphoon/). 


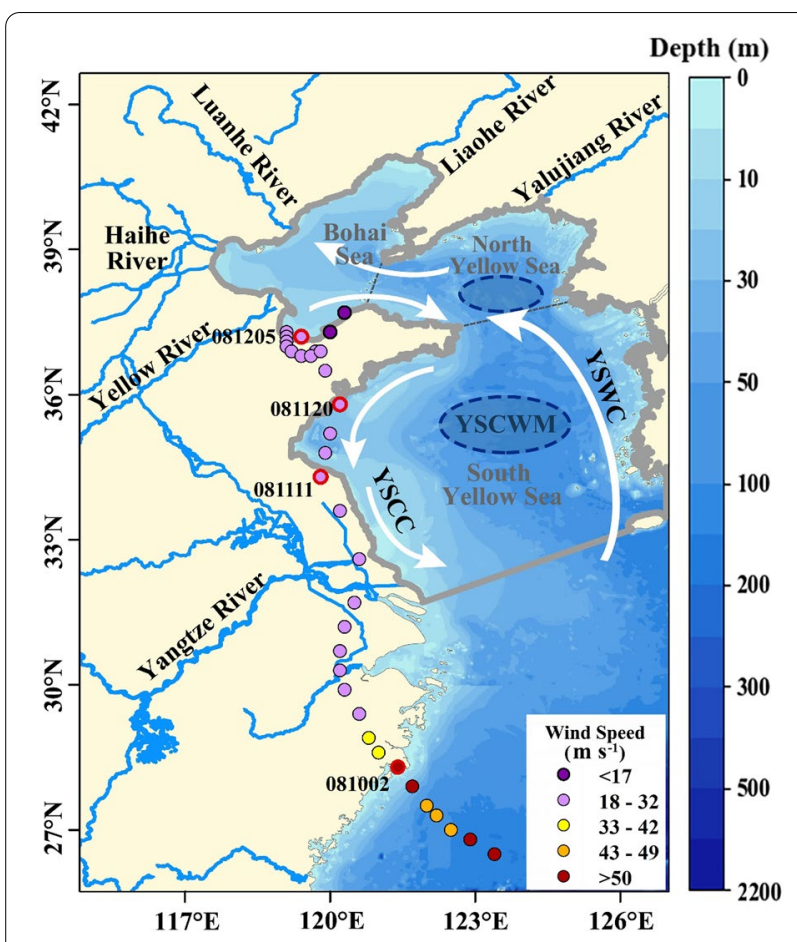

Fig. 1 Bathymetry and current system in the Yellow-Bohai Sea, the main inflow rivers, and the track of Typhoon Lekima (during 4-13th August, 2019). The white lines with arrows denote the Yellow Sea Warm Current (YSWC) and Yellow Sea Coastal Current (YSCC), and blue oval circles the Yellow Sea Cold Water Mass (YSCWM). The track and maximum sustained wind speeds during the Typhoon Lekima event were obtained from China Meteorological Administration (http://www.typhoon.org.cn). Red circles denote typhoon centers at a specific time (Beijing local time, UTC +8 ). The bathymetry data are from ETOPO1 Global Relief Model (Amante and Eakins 2009). Current system is modified from Yu et al. (2021). River routing system is from Resource and Environment Science and Data Center of Chinese Academic of Science (http://www.resdc.cn/data.aspx?DATAID =221)

\section{Data source and processing}

Wind field at $10 \mathrm{~m}$ above sea level was derived from the Cross-Calibrated Multi-Platform (CCMP) product (daily, $0.25^{\circ} \times 0.25^{\circ}$. Rainfall data were the Global Satellite Mapping of Precipitation (GSMaP) product (daily, $0.1^{\circ} \times 0.1^{\circ}$ ). High-resolution current field and salinity data (3-h mean, $0.08^{\circ} \times 0.08^{\circ}$ ) were obtained from output of the Hybrid Coordinate Ocean Model (HYCOM). Sea surface temperature (SST) data were obtained from Optimum Interpolation Sea Surface Temperature (OISST) products (daily, $0.25^{\circ} \times 0.25^{\circ}$ ). Chl-a and POC data were derived from Level 3 Standard Mapped Image products (daily, $4 \mathrm{~km} \times 4 \mathrm{~km}$ ) from Moderate Resolution Imaging Spectroradiometer (MODIS) onboard Aqua, in which atmospheric correction using near-infrared bands was applied. These data have been widely used in relevant studies and showed acceptable accuracy (Cui et al. 2014; Fan et al. 2018; Fu et al. 2016a, b; Ning et al. 2017; Zhao et al. 2019).

There may be abnormal values in Chl-a and POC data (i.e., overestimation during retrieval), since the coastal waters in YBS are a typical case II water, in which optical properties are influenced by both phytoplankton and exogenous materials. According to previous field measurements, we set $45 \mathrm{mg} \mathrm{m}^{-3}$ and $1400 \mathrm{mg} \mathrm{m}^{-3}$ as the thresholds for Chl-a and POC, respectively (Fan et al. 2018; Mao et al. 2017; Sun et al. 2019; Wang et al. 2018). Values greater than the thresholds were replaced with the average value of surrounding points, which accounted $\sim 0.07 \%$ and $\sim 0.33 \%$ of total data points for $\mathrm{Chl}-\mathrm{a}$ and POC, respectively. Because reflectance of seabed could also affect optical properties of coastal water, we only used data in regions with bathymetry $>5 \mathrm{~m}$ in our analyses. Due to low coverage of the ocean color data during the typhoon events, we selected multi-day composited data over three periods: prior to (1-8th August for the BS and NYS, and 30th July-6th August for the SYS), during (11-13th August), and post (14-21st August) Typhoon Lekima. We used different time frames for the prior-typhoon period (i.e., 2 days earlier for the SYS) to reflect the difference in timing of typhoon. Mean filter was applied to reduce abrupt changes caused by mosaic operation. In this study, data processing, calculation, and statistical analyses were conducted using MATLAB 2018a and ArcMap 10.5.

\section{Results}

\section{Changes of environmental conditions}

The Typhoon Lekima event caused strong winds and heavy rainfall over most parts of the YBS. The wind was weak $\left(<6 \mathrm{~m} \mathrm{~s}^{-1}\right)$ in the YBS prior to the typhoon event (1-8th August) (Fig. 2d). Due to passage of the typhoon, strong winds prevailed, with wind speed $>9 \mathrm{~m} \mathrm{~s}^{-1}$ during the typhoon event (11-13th August) in most sections of YBS (Fig. 2e). Similarly, relatively light rainfall $\left(<0.5 \mathrm{~mm} \mathrm{~h}^{-1}\right)$ generally occurred in the YBS prior to the typhoon event (1-8th August) (Fig. 3d). However, rainfall increased in majority of the YBS during the passage of Typhoon Lekima (11-13th August), with intensive rainfall $\left(>0.75 \mathrm{~mm} \mathrm{~h}^{-1}\right)$ in the central SYS, northern YBS, and adjacent lands (Fig. 3e).

Strong wind during Typhoon Lekima (11-13th August) enhanced current $\left(>0.2 \mathrm{~m} \mathrm{~s}^{-1}\right)$ and upwelling $\left(0.4-3 \times 10^{-5} \mathrm{~m} \mathrm{~s}^{-1}\right)$ in most sections of the YBS, which were much stronger than the current $\left(<0.15 \mathrm{~m} \mathrm{~s}^{-1}\right)$ and upwelling $\left(<1.5 \times 10^{-6} \mathrm{~m} \mathrm{~s}^{-1}\right)$ during non-typhoon periods (Additional file 1: Figs. S1, S2). Heavy rainfall during the typhoon event (11-13th August) led to intensive flooding and runoff around the YBS, with $\sim 70$ intensely flooded rivers, in which the Yellow River's runoff reached 


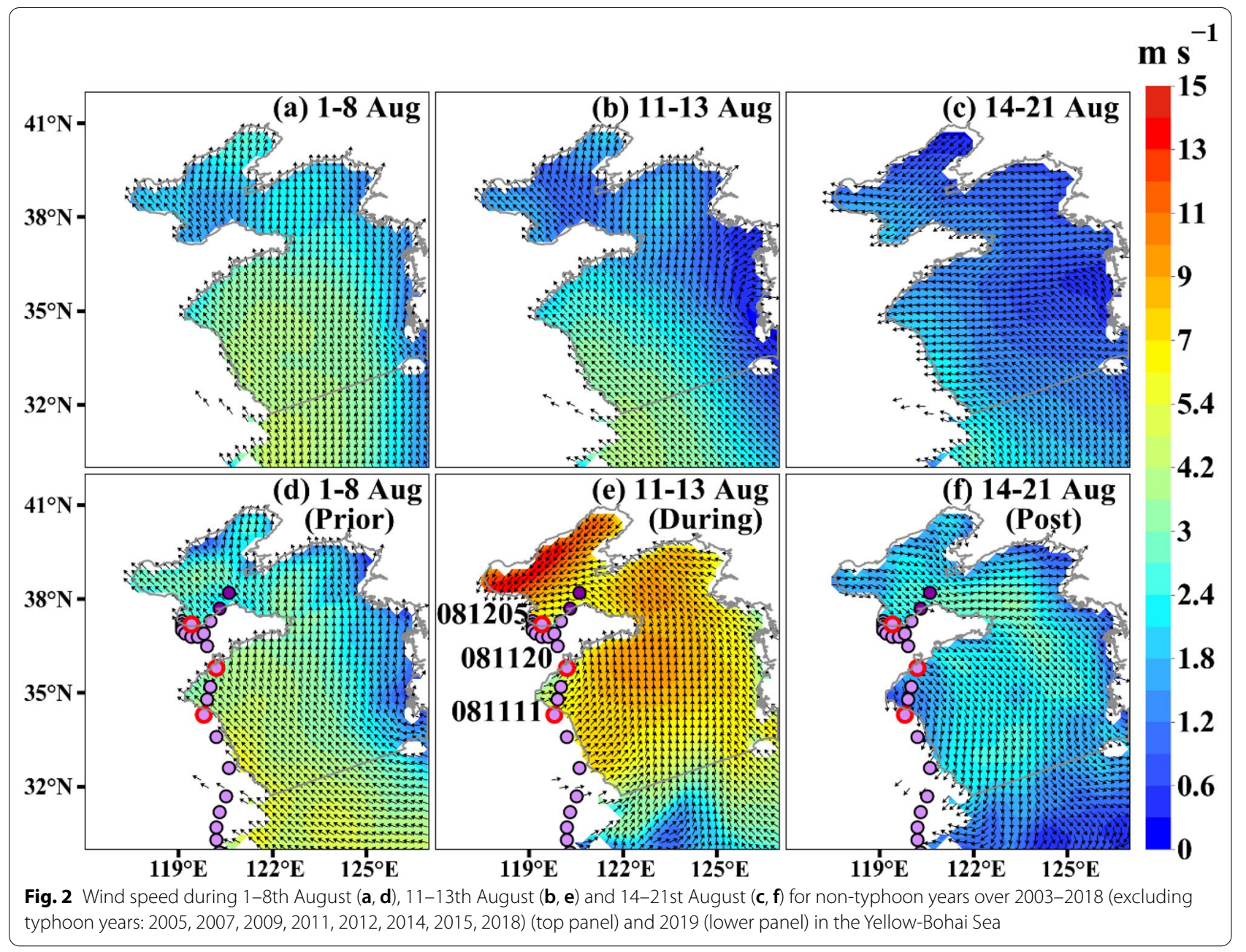

$3990 \mathrm{~m}^{3} \mathrm{~s}^{-1}$, which was much greater than those (1500$2500 \mathrm{~m}^{3} \mathrm{~s}^{-1}$ ) in non-typhoon years (according to Annual Report of Chinese Hydroregime, http://www.mwr.gov. $\mathrm{cn} / \mathrm{sj} /$ tjgb/sqnb).

\section{Responses of Chl-a and POC}

In non-typhoon years, Chl-a increased markedly from 1-8th to 14-21st August in most sections of the YBS, but decreased slightly in some parts of western SYS (Fig. 4c). On average, the increase of Chl-a was $0.12 \mathrm{mg} \mathrm{m}^{-3}(6 \%)$, $0.68 \mathrm{mg} \mathrm{m}^{-3}(39 \%)$, and $0.92 \mathrm{mg} \mathrm{m}^{-3}(20 \%)$ over this period in the SYS, NYS, and BS, respectively (Table 1). In 2019, Chl-a level was higher in almost the entire YS post the Typhoon Lekima event (14-21st August) relative to prior-typhoon conditions (1-8th August), except in the northern coastal waters of the SYS where modest decline (by $<1 \mathrm{mg} \mathrm{m}^{-3}$ ) appeared (Fig. 4f). For the BS, Chl-a showed a significant increase (by $0.5-4 \mathrm{mg} \mathrm{m}^{-3}$ ) in the western part and a modest decrease (by $>1 \mathrm{mg} \mathrm{m}^{-3}$ ) in the middle section. There was a larger increase of Chl-a post the typhoon event (14-21st August) in the NYS (by $0.54 \mathrm{mg} \mathrm{m}^{-3}$ or $\left.46 \%\right)$ than in the SYS $\left(0.23 \mathrm{mg} \mathrm{m}^{-3}\right.$ or $16 \%$ ), but a decrease in the BS (by $0.34 \mathrm{mg} \mathrm{m}^{-3}$ or $7 \%$ ) (Table 1).

Overall, POC increased from 1-8th to 14-21st August in non-typhoon years in most parts of the YBS, except in some sections in the western SYS (Fig. 5c). On average, increase of POC was $9 \mathrm{mg} \mathrm{m}^{-3}, 36 \mathrm{mg} \mathrm{m}^{-3}$, and $45 \mathrm{mg} \mathrm{m}^{-3}$ in the SYS, NYS, and BS, respectively (Table 1). Compared with those prior to Typhoon Lekima (1-8th August), POC increased after the Typhoon Lekima event in majority of the YBS, with a small decrease in northwest coastal SYS and the central BS near the Bohai Strait (Fig. 5f). On average, the increase of POC was greatest in the NYS (by $79 \mathrm{mg} \mathrm{m}^{-3}$ or $46 \%$ ) and smallest in SYS (by $41 \mathrm{mg} \mathrm{m}^{-3}$ or $22 \%$ ), and in between in the BS (by $78 \mathrm{mg} \mathrm{m}^{-3}$ or $24 \%$ ) (Table 1 ). 


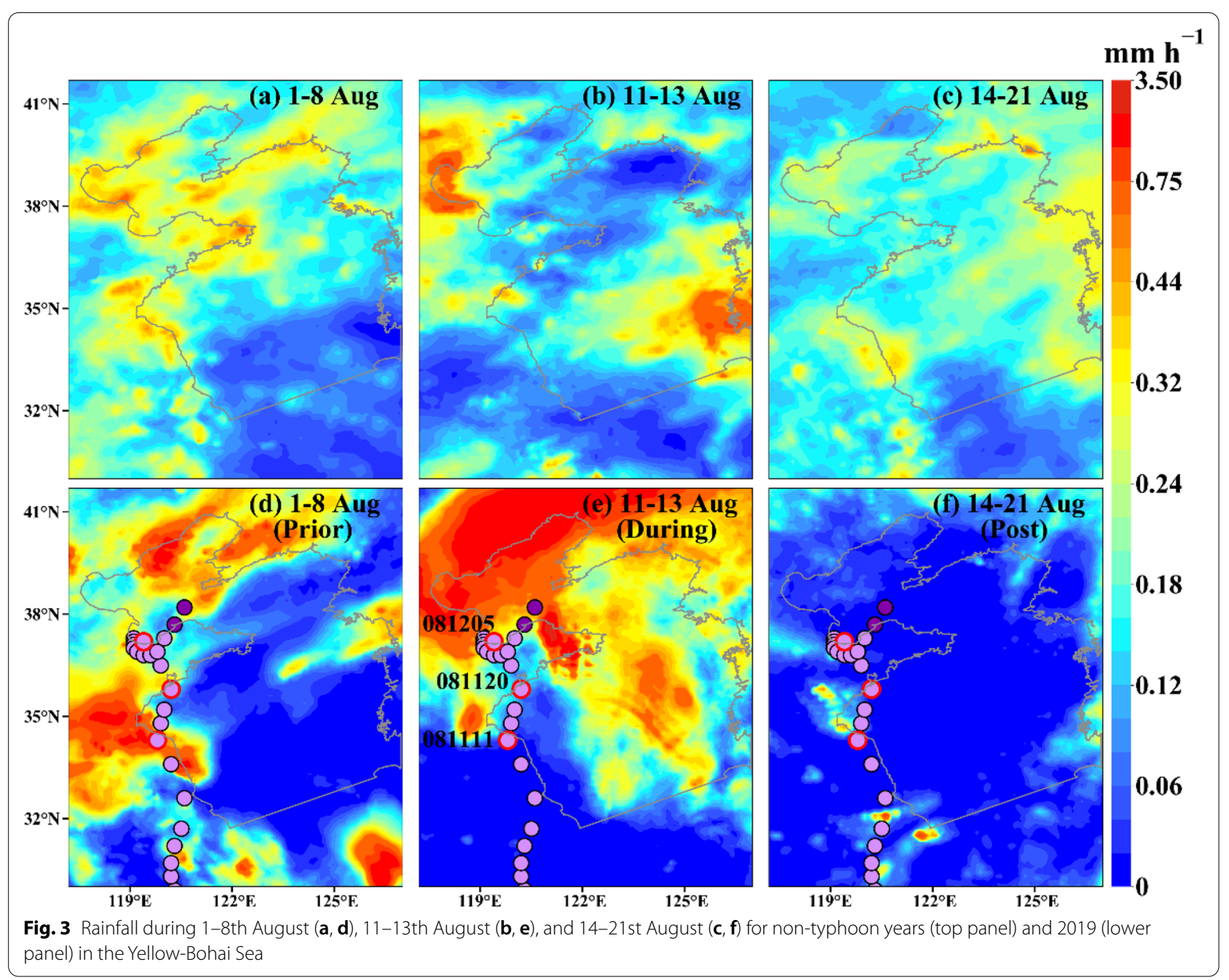

\section{Variations of POC:Chl-a ratio}

The POC:Chl-a ratio is often used to indicate the contribution of phytoplankton carbon to total POC in seawaters (Hung et al. 2010; Yu et al. 2019). Clearly, POC:Chl-a ratio was lower in nearshore waters $(\sim 50-100)$ than in offshore waters $(>150)$ in both non-typhoon years and 2019 (Fig. 6). A field study also reported a high-POC:Chla ratio $(>140)$ in summer in the offshore waters of YS (Wang et al. 2018). The spatial variation of POC:Chl-a ratio was large in non-typhoon years, showing relatively large areas of both low ratio $(<100)$ and high ratio $(>200)$ waters (Fig. 6a, b). There was an overall decrease in the POC:Chl-a ratio from 1-8th to 14-21st August except in some nearshore waters during non-typhoon years (Fig. 6c), with the largest decrease in the NYS (by 23 \pm 33 ) followed by in the SYS $(10 \pm 22)$ and in the BS $(4 \pm 12)$ (Table 1). However, POC:Chl-a ratio showed an increase (by $\sim 10-100)$ post the Typhoon Lekima event (14-21st August) in most sections of the YBS, but a small decrease (by < 45) in some coastal sections, e.g., in the eastern YS and southwestern BS (Fig. 6f). On average, the increase in POC:Chl-a ratio was $18 \pm 38$ in the SYS, $8 \pm 28$ in NYS and $22 \pm 23$ in the BS (Table 1).

\section{Discussion}

\section{Impacts of typhoons on environmental conditions} of marginal seas

Typhoon events usually cause stronger wind and thus upwelling, which brings cold water into the surface layer, resulting in a decrease in SST (Liu et al. 2019; Zheng and Tang 2007). Our results showed a decrease in SST associated with enhanced upwelling (Additional file 1: Fig. S3), particularly in the western YBS near to the tracks of Typhoon Lekima, which was consistent with other studies that reported surface cooling under strengthened upwelling (Liu et al. 2019, 2020a). Apart from the impact of upwelling, there was also evidence of further SST decrease due to input of extra 


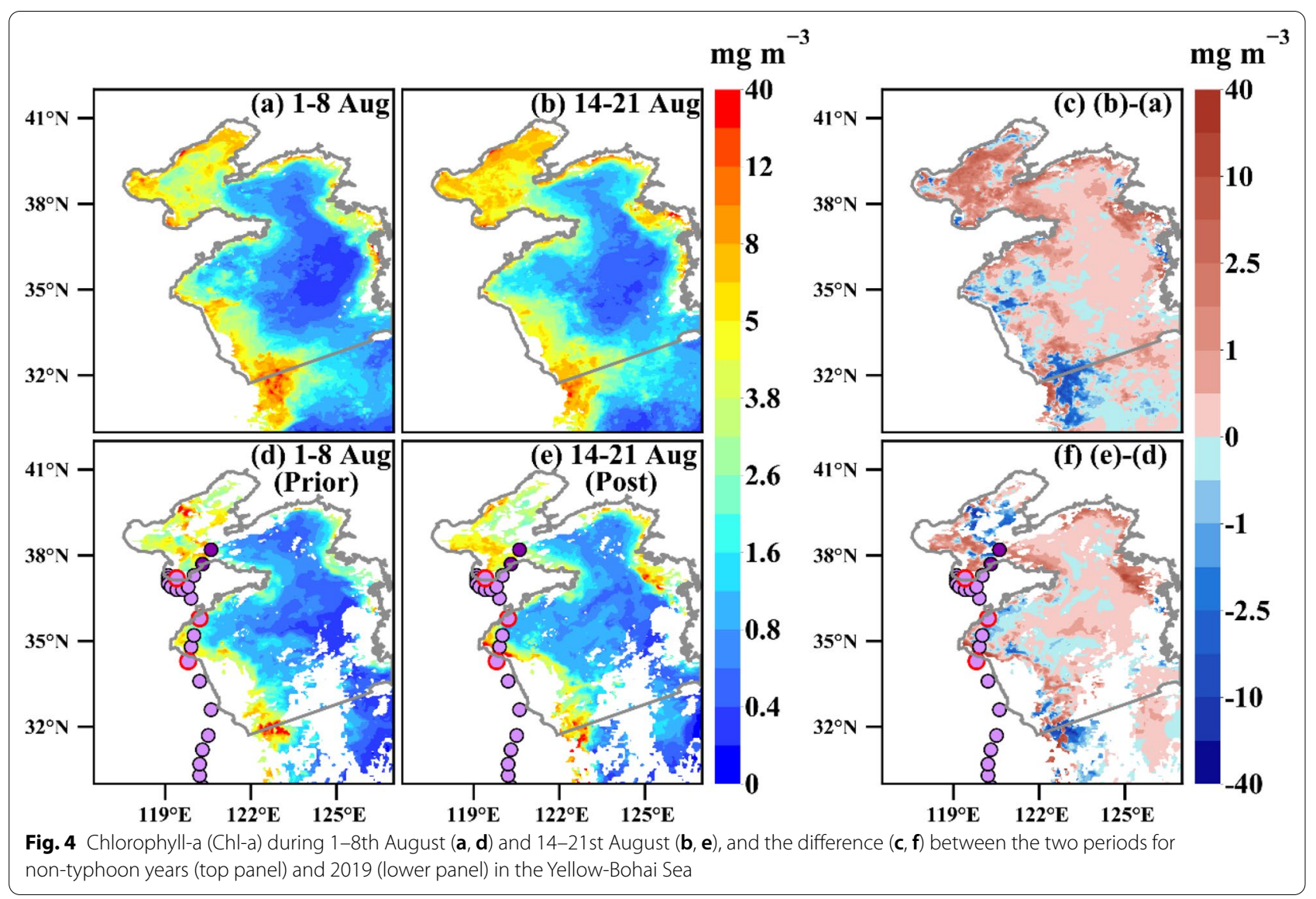

Table 1 Means (standard deviations) of Chl-a $\left(\mathrm{mg} \mathrm{m}^{-3}\right)$ and POC $\left(\mathrm{mg} \mathrm{m}^{-3}\right)$ and their changes (percentages) from 1-8th to 14-21st in August of 2019 and non-typhoon years over 2003-2018

\begin{tabular}{|c|c|c|c|c|c|c|}
\hline & \multicolumn{2}{|l|}{ Bohai Sea } & \multicolumn{2}{|c|}{ North Yellow Sea } & \multicolumn{2}{|c|}{ South Yellow Sea } \\
\hline & $2003-2018$ & 2019 & $2003-2018$ & 2019 & $2003-2018$ & 2019 \\
\hline \multicolumn{7}{|l|}{ Chl-a } \\
\hline 1-8th August & $4.67(1.7)$ & $4.63(2.7)$ & $1.73(1.6)$ & $1.18(1.0)$ & $1.83(1.9)$ & $1.50(1.7)$ \\
\hline 14-21st August & $5.58(1.6)$ & $4.29(1.4)$ & $2.41(2.2)$ & $1.72(1.5)$ & $1.95(1.8)$ & $1.74(2.1)$ \\
\hline Change (percentage) & $0.92(20 \%)$ & $-0.34(-7 \%)$ & $0.68(39 \%)$ & $0.54(46 \%)$ & $0.12(6 \%)$ & $0.23(16 \%)$ \\
\hline \multicolumn{7}{|l|}{$\mathrm{POC}$} \\
\hline 1-8th August & $376(67)$ & $329(84)$ & $220(102)$ & $170(73)$ & $201(100)$ & $183(1.6)$ \\
\hline 14-21st August & $421(58)$ & $407(61)$ & $255(120)$ & $249(117)$ & $210(96)$ & $224(110)$ \\
\hline Change (percentage) & $45(12 \%)$ & $78(24 \%)$ & $36(16 \%)$ & $79(46 \%)$ & $9(4 \%)$ & $41(22 \%)$ \\
\hline \multicolumn{7}{|l|}{ POC:Chl-a } \\
\hline 1-8th August & $92(16)$ & $78(18)$ & $174(49)$ & $170(35)$ & $169(59)$ & $163(48)$ \\
\hline 14-21st August & $88(11)$ & $100(17)$ & $151(41)$ & $178(44)$ & $159(52)$ & $182(59)$ \\
\hline
\end{tabular}

freshwater (with lower temperature) from heavy rainfall and enhanced runoff (Fu et al. 2016a, b). On the other hand, the freshwater input could also enhance ocean stratification and suppress vertical mixing due to decreased sea surface salinity, which could reduce the decline of SST (Liu et al. 2020b). Our analysis also showed a decrease of salinity in most nearshore waters (Additional file 1: Fig. S4), reflecting the dilution effect caused by heavy rainfall and enhanced freshwater inputs from coastline runoff. 


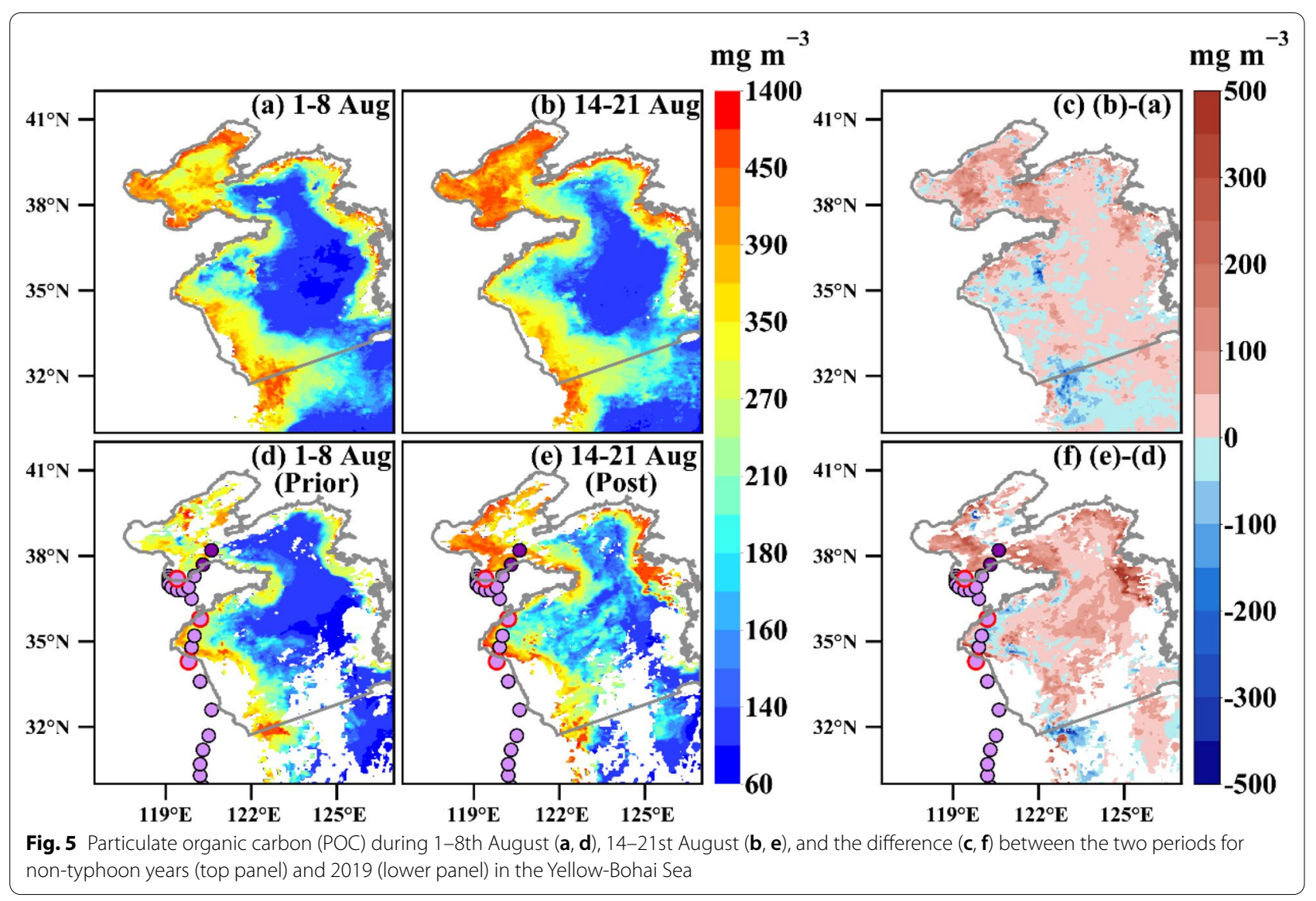

Previous studies have reported significant increases in nutrients following typhoon events (Hung et al. 2013; Jiang et al. 2020), which often results from strengthened upwelling that brings more nutrients from bottom waters into surface layer (Liu et al. 2019; Zheng and Tang 2007). In addition, enhanced runoff could also deliver more nutrients into coastal waters (Fu et al. 2016a, b). Indeed, a recent field study showed that total inorganic nitrogen concentrations increased by $>90 \%$ in coastal waters of the NYS post the Typhoon Lekima 2019 (Lu et al. 2020), implying that there would be consequently biological responses.

\section{Biological responses to typhoon-induced environment changes}

There was evidence of increased Chl-a following typhoon events, which was attributed to enhanced nutrient supply associated with typhoon-enhanced terrestrial runoff and upwelling (Shiah et al. 2000). Although our study showed lower Chl-a levels during 14-21 August in 2019 (post the Typhoon Lekima event) than in non-typhoon years, the relative increase of Chl-a (from 1-8th to 14-21st August) was greater in $2019(16-46 \%)$ than in non-typhoon years $(6-39 \%)$ in the YS (Table 1), indicating that phytoplankton growth increased in association with the passage of Typhoon Lekima. In addition, the increase of Chl-a post-typhoon events could be partly due to upwelling of phytoplankton from subsurface into surface in the sections with subsurface Chl-a maximum (Chen et al. 2017; Liu et al. 2019), suggesting that the increase of Chl-a in the surface of SYS might be partly attributable to the upwelling of high-Chl-a water from subsurface (Fu et al. 2018). There was also evidence of changes in community structure post-typhoon events, i.e., more abundance in large size of phytoplankton that often has a higher Chla:carbon ratio (Frenette et al. 1996; Ma et al. 2021; Sun et al. 2002; Wei et al. 2017).

Earlier studies reported a large increase of Chl-a (usually by $\sim 50-100 \%$ ) after typhoon events in shallow waters of the Northwest Pacific, e.g., in the northern South China Sea due to enhanced nutrient supply. However, we found that the increase of Chl-a was much smaller (1646\%) in the YS following the passage of Typhoon Lekima that lasted for only $\sim 9 \mathrm{~h}$. In addition, the intensity of Typhoon Lekima was weak in the YS, causing much weaker Ekman upwelling $\left(0.5-3.5 \times 10^{-5} \mathrm{~m} \mathrm{~s}^{-1}\right)$, relative to those $\left(1.0-480 \times 10^{-5} \mathrm{~m} \mathrm{~s}^{-1}\right)$ with other typhoon 


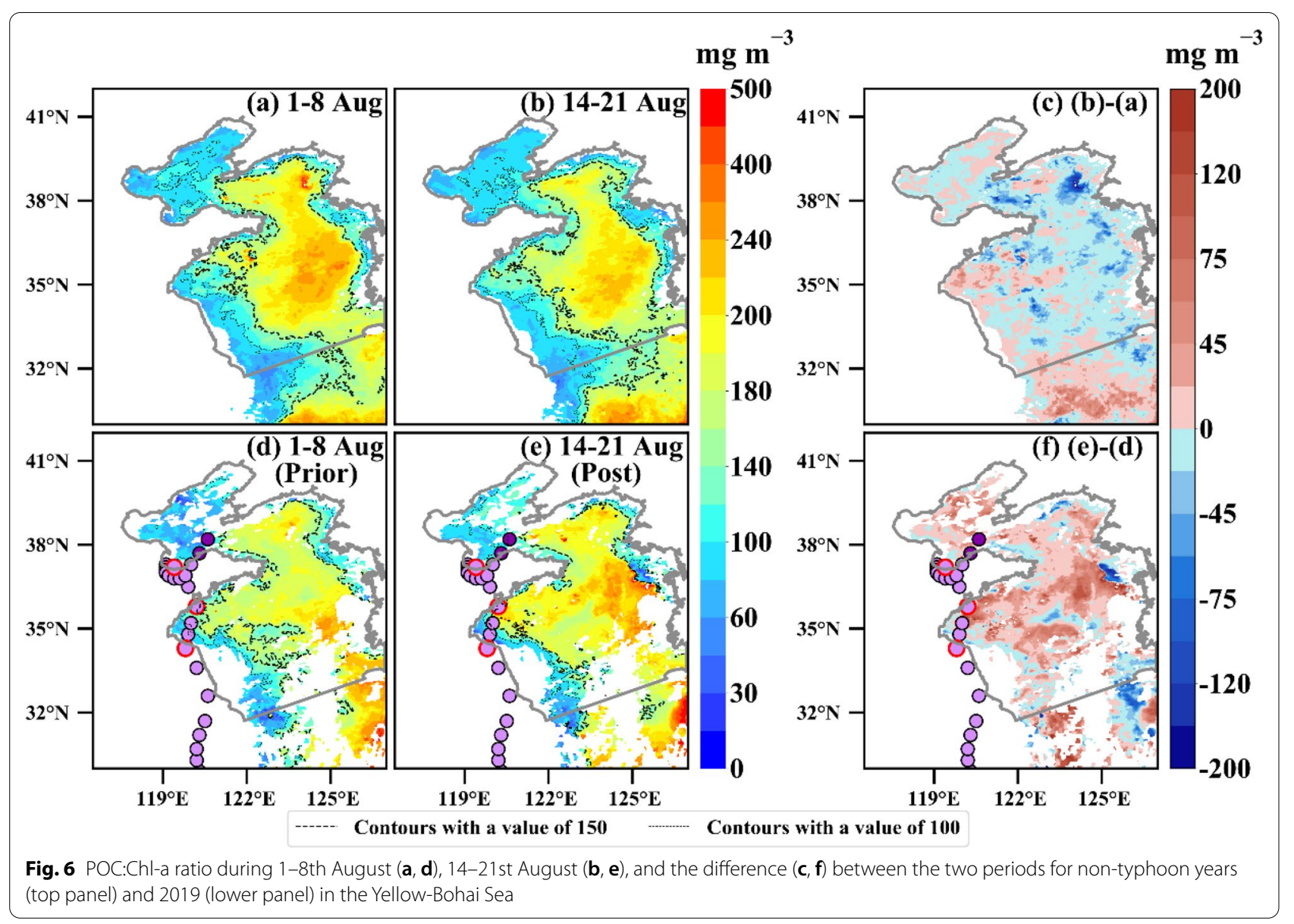

events (Pan et al. 2017; Sun et al. 2010; Zhao et al. 2008), which was largely responsible for the small increase in $\mathrm{Chl}-\mathrm{a}$. The obvious difference in the relative increase of Chl-a was also attributed to the difference in Chl-a baseline, i.e., much higher in the YS $\left(>0.8 \mathrm{mg} \mathrm{m}^{-3}\right)$ but lower in those oligotrophic seawaters $\left(<0.25 \mathrm{mg} \mathrm{m}^{-3}\right)$ (Liu et al. 2019; Zhao et al. 2008).

Our results also revealed the decreases of Chl-a in the middle BS and northwestern coastal SYS shortly after the passage of Typhoon Lekima, where strong upwelling prevailed during the Typhoon Lekima event. Previous studies reported decreased Chl-a post-typhoon events, which was partly due to perturbation caused by bottom water entrainment (Shih et al. 2020), or attributed to dilution and flushing induced by elevated freshwater discharge (Huang et al. 2011; Wiegner et al. 2012). Apparently, the heavy rainfall brought by the Typhoon Lekima event would have dilution effects on Chl-a, particularly in the BS (Fig. 3e). In addition, enhanced surface current associated with the Typhoon Lekima transported low Chl-a seawater from the NYS to the central BS (Additional file 1: Fig. S1e), as indicated by the co-occurrence of a significant decrease in Chl-a (Fig. 4f) and increase in salinity (Additional file 1: Fig. S4d). Moreover, water column was not stable due to increased current velocity (Additional file 1: Fig. S1e), which could affect phytoplankton growth and depress the pre-existing bloom (Long et al. 2011; Mitrovic et al. 2003). The decline of Chl-a in the SYS was also partly caused by dilution and flushing due to massive freshwater discharge. In addition, there was evidence that enhanced terrestrial runoff caused further phosphorus limitation in the SYS due to the low-phosphorus concentration in runoff from adjacent lands (Guo et al. 2020; Lian et al. 2020), which could lead to lower Chl-a. While phytoplankton growth could be restrained by light limitation due to sediments resuspension caused by typhoon events (Ding et al. 2012; Hung et al. 2010), our analyses did not show light limitation in most typhoon-affected sections, as indicated by deepened euphotic depth (Additional file 1: Fig. S5).

\section{Impacts of typhoon on organic carbon in marginal seas}

Previous studies reported significant increases of POC (>60\%) post-typhoon events in marginal seas in the 
Northwest Pacific, e.g., the south East China Sea, which were largely caused by typhoon-induced phytoplankton blooms (Hung et al. 2010; Shiah et al. 2000). Our analyses showed a modest increase of POC (22-46\%) in the YBS post the Typhoon Lekima event, which might be attributable to the small increase of phytoplankton biomass [indicated by the small increase of Chl-a (16-46\%)], due to the short duration and weak intensity of Typhoon Lekima in the YBS and its less extent of impacts.

The increase of POC from 1-8th to 14-21st August was much greater in $2019\left(41-79 \mathrm{mg} \mathrm{m}^{-3}\right.$, or $\left.22-46 \%\right)$ than in non-typhoon years $\left(9-45 \mathrm{mg} \mathrm{m}^{-3}\right.$, or $\left.4-16 \%\right)$ in the YBS (Table 1). The BS revealed increased POC with decreased Chl-a post the Typhoon Lekima event (Table 1), and a larger intercept ( 83 vs. 20 ) in the correlation between the change of POC and the change of Chl-a $(\Delta \mathrm{POC}-\Delta \mathrm{Chl}-\mathrm{a})$ in 2019 than in non-typhoon years (Fig. 7), indicating that there were other sources rather than marine ecosystem responsible for the increase of POC associated with the Typhoon Lekima event. A recent study also reported that typhoon-induced changes in physical processes had effects on POC level in the coastal Japan Sea (Tsuchiya et al. 2017). Strong wind in association with the Typhoon Lekima event could increase injection of sedimentary POC to the surface layer via enhanced resuspension and wind driven upwelling in the BS, and similar findings were reported in other marginal seas (Dickey et al. 1998; Shiah et al. 2000). In addition, enhanced runoff associated
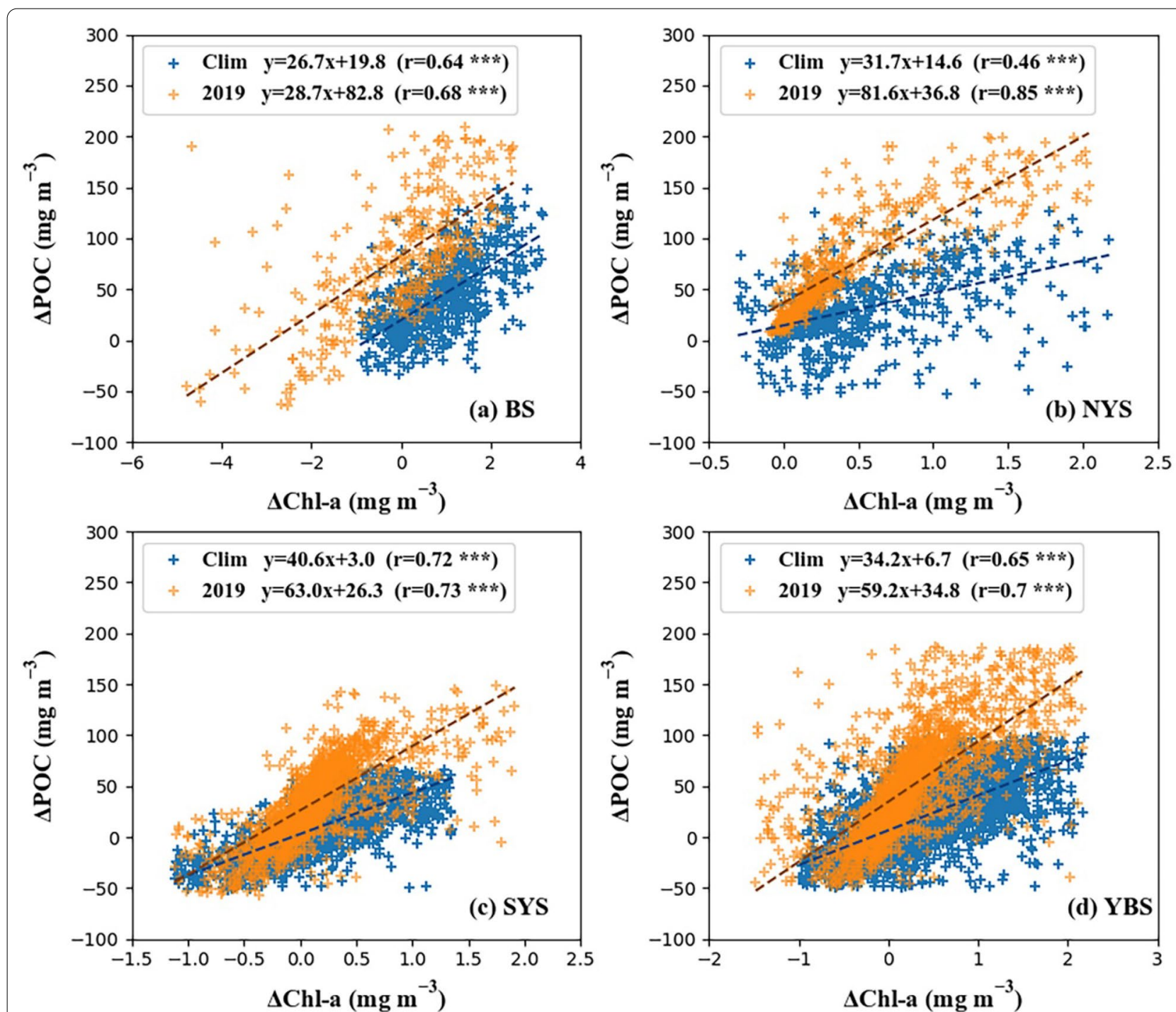

Fig. 7 Correlation analyses for the changes of POC $(\triangle P O C)$ and chlorophyll-a ( $\triangle C h l-a)$ from 1-8th to 14-21st August for non-typhoon years and 2019 in the Bohai Sea (BS), north Yellow Sea (NYS), south Yellow Sea (SYS), and Yellow-Bohai Sea (YBS) 
with heavy rainfall (as indicated by the decrease of salinity, see Additional file 1: Fig. S4d) could also bring more terrigenous POC into the coastal waters of BS, as discussed in a previous study (Yu et al. 2018). On the other hand, the reduction of POC in the central BS near the Bohai Strait was attributed to enhanced water exchange with the low-POC water from the NYS (Additional file 1: Fig. S1e).

There were considerable differences in the response to the Typhoon Lekima event between POC and Chl-a in the YS (Figs. 4f, 5f). We evaluated the variation of POC:Chl-a ratio (an index used to assess the sources of POC in the oceans), in which a small POC:Chl-a ratio $(<200)$ indicates a large contribution of phytoplankton to POC (Hung et al. 2010; Yu et al. 2019). Our analyses showed that there was a decrease in POC:Chl-a ratio (by 10-23) in the YS from 1-8th to 14-21st August in non-typhoon years, indicating that biological production was the main driver responsible for the increase of POC in summer (Yu et al. 2019). However, POC:Chl-a ratio revealed an increase post-Typhoon Lekima in the YS except in the coastal waters of the NYS. There was evidence that large-size phytoplankton bloom post-typhoon events could result in lower POC:Chl-a ratio, particularly in nearshore waters (Lee et al. 2020).

Our further analyses demonstrated that there was a significantly positive correlation between the increase of POC and the increase of Chl-a from 1-8th to 14-21st August; the slope of $\Delta \mathrm{POC}-\Delta \mathrm{Chl}$-a correlation (as shown in Fig. 7) was much greater in 2019 (63-81) than in non-typhoon years (32-41) in the YS, suggesting that there were other processes in addition to biological production contributing elevated POC. Previous studies reported that apart from biological contribution, the dynamics of POC in the YBS was largely regulated by terrestrial inputs, sediment resuspension, and water exchange (Fan et al. 2018; Yu et al. 2018). For example, sedimentary resuspension is one of the major processes causing high level of the POC in the YBS (Fan et al. 2018). There was also evidence of significant sedimentary POC supply during typhoon events in other marginal seas, owing to stronger upwelling and enhanced resuspension resulting from strong winds (Dickey et al. 1998; Shiah et al. 2000).

There was evidence that terrigenous POC could be transported via large rivers and coastline runoff into nearshore waters of marginal seas (Qiao et al. 2020; Trefry et al. 1994; Wang et al. 2012). Our study showed an increase in POC:Chl-a ratio in the coastal waters of SYS (Fig. 6f), indicating that there might be other sources of POC during the Typhoon Lekima event. The typhooninduced heavy rainfall could enhance runoff along the coastline, which would inject extra terrigenous POC into the nearshore waters. In addition, the further northward extension of Yangtze River Diluted Water during typhoon events (Oh et al. 2014) could also transport more terrigenous POC into the SYS. On the other hand, elevated POC:Chl-a ratio (due to greater increase in POC) in the central sections of YS might reflect strengthened current resulting from Typhoon Lekima, which could transport high-POC waters from nearshore to offshore.

Previous studies reported lower levels of Chl-a and POC in summer than in spring and autumn in the YBS due to poor nutrient supply and weak sediment resuspension via restrained vertical mixing caused by stronger stratification (Fan et al. 2018; Zhao et al. 2019). The increases of Chl-a and POC in the YBS caused by Typhoon Lekima were lower than the seasonal increases (from summer to autumn), indicating that the influences of Typhoon Lekima on the biogeochemical processes were insignificant. The YBS had been impacted by various typhoon events over the recent decades, which occurred in $>50 \%$ of the summer seasons with 1-4 passages in each season. There was another typhoon event (Typhoon Danas) prior to Typhoon Lekima, which could cause changes in environmental conditions, thus alter the responses of biological and chemical processes. Apparently, the interactive responses of physical and biological processes to typhoon events were complex, which would have significant impacts on the nutrients and carbon cycle in the YBS. Future studies with in situ measurements of critical carbon cycle parameters and process-orientated modeling studies warrant better understanding the impacts of typhoons on the carbon cycle in marginal seas.

\section{Conclusions}

We analyzed the responses of key physical and biological parameters in the YBS to the Typhoon Lekima event, which included wind speed, rainfall, current, upwelling, Chl-a, and POC. The passage of Typhoon Lekima caused stronger wind and heavier rainfall, which generated stronger upwelling and current in large area of the YBS and enhanced runoff from adjacent lands. Chl-a and POC showed considerable differences in the responses to typhoon-induced environmental changes, with the largest difference found in BS (i.e., an overall decrease in Chl-a but an increase in POC). The decrease $\left(0.34 \pm 3.0 \mathrm{mg} \mathrm{m}^{-3}\right)$ of Chl-a in the BS was mainly caused by dilution due to freshwater inputs from heavy rainfall and water exchange with NYS, whereas the increase $\left(0.23-0.54 \mathrm{mg} \mathrm{m}^{-3}\right)$ of Chl-a in the YS was largely attributable to the increase of nutrients caused by enhanced upwelling and terrestrial inputs. There was a basin-scale increase in POC post the typhoon event in the YBS, i.e., $78 \mathrm{mg} \mathrm{m}^{-3}$ or $24 \%$ in the BS, $79 \mathrm{mg} \mathrm{m}^{-3}$ or $46 \%$ in NYS, 
and $41 \mathrm{mg} \mathrm{m}^{-3}$ or $22 \%$ in the SYS, which were much greater than the increases of $9-45 \mathrm{mg} \mathrm{m}^{-3}$ or $4-16 \%$ over the same period in non-typhoon years. The increase of POC in the most parts of BS was largely attributable to sediment resuspension and terrigenous, whereas the reduction of POC in the central BS was caused by inflow of low-POC water from the NYS. Our analysis suggested that in the YS, probably more than half of POC increase post the Typhoon Lekima event resulted from non-biological sources. The supply of sedimentary POC mainly concentrated in the NYS and northwestern SYS, and the riverine inputs played an important role in increasing POC level in the SYS. In addition, transportation of POC from nearshore to offshore might be responsible for the increase of POC in the central YS. More studies involving modeling and in situ water column and seafloor sampling from coastal to offshore before, during, and after an impact of a typhoon are needed to better understand the impact of tropical cyclones on the carbon cycle in marginal seas.

\begin{abstract}
Abbreviations
POC: Particulate organic carbon; YBS: Yellow-Bohai Sea; BS: Bohai Sea; Chl-a: Chlorophyll-a; YS: Yellow Sea; NYS: North Yellow Sea; SYS: South Yellow Sea; YSWC: Yellow Sea Warm Current; YSCC: Yellow Sea Coastal Current; YSCWM: Yellow Sea Cold Water Mass; SST: Sea surface temperature; OISST: Optimum Interpolation Sea Surface Temperature; CCMP: Cross-Calibrated Multi-Platform; GSMaP: Global Satellite Mapping of Precipitation; HYCOM: Hybrid Coordinate Ocean Model; MODIS: Moderate Resolution Imaging Spectroradiometer.
\end{abstract}

\section{Supplementary Information}

The online version contains supplementary material available at https://doi. org/10.1186/s40562-021-00201-y.

Additional file 1: Fig. S1. Current velocity in 1-8th August (a, d), 11-13th August $(b, e)$, and 14-21st August ( $c, f)$ for non-typhoon years (top panel) and 2019 (lower panel) in the Yellow-Bohai Sea. Fig. S2. Ekman Pump velocity in 1-8th August $(a, d), 11-13$ th August $(b, e)$ and 14-21st August $(c, f)$ for non-typhoon years (top panel) and 2019 (lower panel) in the Yellow-Bohai Sea. Fig. S3. Sea Surface Temperature (SST) in 1-8th August (a, d), 11-13th August $(b, e)$ and 14-21st August $(c, f)$ for non-typhoon years (top panel) and 2019 (lower panel) in the Yellow-Bohai Sea. Fig. S4. Sea surface salinity during 1-8th August (a), 11-13th August (b) and 14-21st August (c) for 2019 as well as the difference (d) between the first and last period in the Yellow-Bohai Sea. Fig. S5. Difference of euphotic depth between 1-8th and 14-21st August in 2019 in the Yellow-Bohai Sea.

\section{Acknowledgements}

We are grateful for the constructive comments of two anonymous reviewers.

\section{Authors' contributions}

XiuW provided supervision for this study, and checked/corrected all the versions of the manuscript. XiaW collected research data, conducted data analyses, and prepared for the manuscript. Z-JY provided financial support, and commented on later versions of the manuscript. All authors read and approved the final manuscript.

\section{Authors' information}

Xiujun Wang is a professor and chief scientist at the College of Global Change and Earth System Science, Beijing Normal University. She earned a Ph.D. in ocean biogeochemistry from the Tasmania University (Australia) in 2002, and had nearly 20 years of research experience in oceanic carbon cycle.

\section{Funding}

National Natural Science Foundation of China and the Provincial Natural Science Foundation of Shandong (U1806227).

\section{Availability of data and materials}

CCMP wind field data was acquired from http://www.remss.com. Rainfall data derived from GSMaP product were downloaded from: http://sharaku.eorc.jaxa. jp/GSMaP_crest. Current field and salinity data from output of HYCOM were obtained from https://earthengine.google.com. OISST product was obtained from: https://www.ncdc.noaa.gov/oisst. MODIS-Aqua POC and Chl-a data are available at: https://oceandata.sci.gsfc.nasa.gov/MODIS-Aqua/.

\section{Declarations}

Competing interests

The authors declare that they have no conflict of interests.

\section{Author details}

${ }^{1}$ College of Global Change and Earth System Science, Beijing Normal University, Beijing 100875, China. ${ }^{2}$ Centre for Ports and Maritime Safety, Dalian Maritime University, Dalian 116026, Liaoning, China. ${ }^{3}$ School of Civil Engineering, Ludong University, Yantai 264025, Shandong, China.

Received: 2 August 2021 Accepted: 28 September 2021

Published online: 15 October 2021

\section{References}

Amante C, Eakins BW (2009) ETOPO1 1 arc-minute global relief model: procedures, data sources and analysis. NOAA Technical Memorandum NESDIS NGDC-24. National Geophysical Data Center, NOAA. https://doi.org/10. 7289/N5C8276M. Accessed 26 Jan 2020.

Bauer JE et al (2013) The changing carbon cycle of the coastal ocean. Nature 504(7478):61-70. https://doi.org/10.1038/nature12857

Chen C-TA (2009) Chemical and physical fronts in the Bohai, Yellow and East China seas. J Mar Syst 78(3):394-410. https://doi.org/10.1016/j.jmarsys. 2008.11.016

Chen Y, Tang D (2011) Remote sensing analysis of impact of typhoon on environment in the sea area south of Hainan Island. Procedia Environ Sci 10:1621-1629. https://doi.org/10.1016/j.proenv.2011.09.256

Chen D et al (2017) Effects of typhoon events on chlorophyll and carbon fixation in different regions of the East China Sea. Estuar Coast Shelf Sci 194:229-239. https://doi.org/10.1016/j.ecss.2017.06.026

Cui T et al (2014) Assessment of satellite ocean color products of MERIS, MODIS and SeaWiFS along the East China Coast (in the Yellow Sea and East China Sea). ISPRS J Photogramm Remote Sens 87:137-151. https:// doi.org/10.1016/j.isprsjprs.2013.10.013

Dickey TD et al (1998) Sediment resuspension in the wakes of hurricanes Edouard and Hortense. Geophys Res Lett 25(18):3533-3536. https://doi. org/10.1029/98gl02635

Ding Y et al (2012) Effects of typhoon Morakot on a large shallow lake ecosystem, Lake Taihu, China. Ecohydrology 5(6):798-807. https://doi.org/10. $1002 /$ eco. 270

Fan $\mathrm{H}$ et al (2018) Spatial and temporal variations of particulate organic carbon in the Yellow-Bohai Sea over 2002-2016. Sci Rep. https://doi.org/10.1038/ s41598-018-26373-w

Fang Y et al (2018) Cycling and budgets of organic and black carbon in Coastal Bohai Sea, China: impacts of natural and anthropogenic perturbations. Glob Biogeochem Cycles 32(6):971-986. https://doi.org/10.1029/2017g b005863

Frenette J-J et al (1996) Size-dependent phytoplankton responses to atmospheric forcing in Lake Biwa. J Plankton Res 18(3):371-391. https://doi.org/ 10.1093/plankt/18.3.371

Fu D et al (2016a) Impact of two typhoons on the marine environment in the Yellow Sea and East China Sea. Chin J Oceanol Limnol 34(4):871-884. https://doi.org/10.1007/s00343-016-5049-6 
Fu Y et al (2016b) Temporal-spatial variations and developing trends of Chlorophyll-a in the Bohai Sea, China. Estuar Coast Shelf Sci 173:49-56. https://doi.org/10.1016/j.ecss.2016.02.016

Fu M et al (2018) Structure, characteristics and possible formation mechanisms of the subsurface chlorophyll maximum in the Yellow Sea Cold Water Mass. Cont Shelf Res 165:93-105. https://doi.org/10.1016/j.csr.2018.07.007

Gao X et al (2021) Particulate organic matter as causative factor to eutrophication of subtropical deep freshwater: role of typhoon (tropical cyclone) in the nutrient cycling. Water Res 188:116470. https://doi.org/10.1016/j. watres.2020.116470

Guo C et al (2020) Seasonal responses of nutrient to hydrology and biology in the southern Yellow Sea. Cont Shelf Res. https://doi.org/10.1016/j.csr. 2020.104207

Hernandez WJ et al (2020) Quantifying the effects of hurricanes irma and maria on coastal water quality in puerto rico using moderate resolution satellite sensors. Remote Sens 12(6):964. https://doi.org/10.3390/rs120 60964

Huang W et al (2011) Assessment of Hurricane Ivan impact on chlorophylla in Pensacola Bay by MODIS $250 \mathrm{~m}$ remote sensing. Mar Pollut Bull 62(3):490-498. https://doi.org/10.1016/j.marpolbul.2010.12.010

Hung CC et al (2010) The effect of typhoon on particulate organic carbon flux in the southern East China Sea. Biogeosciences 7(10):3007-3018. https:// doi.org/10.5194/bg-7-3007-2010

Hung C-C et al (2013) Nutrient supply in the Southern East China Sea after Typhoon Morakot. J Mar Res 71(1-2):133-149. https://doi.org/10.1357/ 002224013807343425

Jiang C et al (2020) Typhoon Merbok induced upwelling impact on material transport in the coastal northern South China Sea. PLoS ONE 15(2):e0228220. https://doi.org/10.1371/journal.pone.0228220

Lee D et al (2020) Estimation of the particulate organic carbon to chlorophylla ratio using MODIS-Aqua in the East/Japan Sea, South Korea. Remote Sensing 12(5):840. https://doi.org/10.3390/rs12050840

Lian X-Q et al (2020) Effect of heavy rainfall on nitrogen and phosphorus concentrations in rivers at river-net plain. Environ Sci 41(11):4970-4980. https://doi.org/10.13227/j.hjkx.202003183

Liu K-K et al (2007) Carbon and nitrogen isotopic compositions of particulate organic matter and biogeochemical processes in the eutrophic Danshuei Estuary in northern Taiwan. Sci Total Environ 382(1):103-120. https://doi. org/10.1016/j.scitotenv.2007.04.019

Liu Y et al (2019) Chlorophyll concentration response to the typhoon wind-pump induced upper ocean processes considering air-sea heat exchange. Remote Sens 11(15):1825. https://doi.org/10.3390/rs11151825

Liu S et al (2020a) Basin-wide responses of the South China Sea environment to Super Typhoon Mangkhut (2018). Sci Total Environ. https://doi.org/10. 1016/j.scitotenv.2020.139093

Liu F et al (2020b) Importance of precipitation on the upper ocean salinity response to Typhoon Kalmaegi (2014). Water 12(2):614. https://doi.org/ 10.3390/w12020614

Long T-Y et al (2011) Numerical simulation for impacts of hydrodynamic conditions on algae growth in Chongqing Section of Jialing River, China. Ecol Model 222(1):112-119. https://doi.org/10.1016/j.ecolmodel.2010.09.028

Lu L et al (2020) Impact of three typhoon events upon surface water of Sanggou Bay and Ailian Bay. Adv Environ Prot 10(1):34061. https://doi. org/10.12677/aep.2020.101005

Ma C et al (2021) Assessing responses of phytoplankton to consecutive typhoons by combining Argo, remote sensing and numerical simulation data. Sci Total Environ. https://doi.org/10.1016/j.scitotenv.2021.148086

Mao X et al (2017) Analysis of chlorophyll-a correlation to determine nutrient limitations in the Coastal Waters of the Bohai Sea, China. J Coast Res 33(2):396-407. https://doi.org/10.2112/jcoastres-d-16-00023.1

Mitrovic SM et al (2003) Critical flow velocities for the growth and dominance of Anabaena circinalis in some turbid freshwater rivers. Freshw Biol 48(1):164-174. https://doi.org/10.1046/j.1365-2427.2003.00957.x

Ning SW et al (2017) Error analysis and evaluation of the latest GSMap and IMERG precipitation products over Eastern China. Adv Meteorol. https:// doi.org/10.1155/2017/1803492

Ning J et al (2019) Upper ocean response to two sequential tropical cyclones over the Northwestern Pacific Ocean. Remote Sens 11(20):2431. https:// doi.org/10.3390/rs11202431
Oh K-H et al (2014) Intrusion of low-salinity water into the Yellow Sea Interior in 2012. Ocean Sci J 49(4):343-356. https://doi.org/10.1007/ s12601-014-0032-7

Paerl HW et al (2020) Recent increases of rainfall and flooding from tropical cyclones (TCS) in North Carolina (USA): implications for organic matter and nutrient cycling in coastal watersheds. Biogeochemistry 150(2):197216. https://doi.org/10.1007/s10533-020-00693-4

Pan G et al (2017) Marine phytoplankton biomass responses to typhoon events in the South China Sea based on physical-biogeochemical model. Ecol Model 356:38-47. https://doi.org/10.1016/j.ecolmodel.2017.04.013

Pan J et al (2018) Quantification of typhoon-induced phytoplankton blooms using satellite multi-sensor data. Remote Sens 10(2):318. https://doi.org/ $10.3390 /$ rs10020318

Qiao J et al (2020) Runoff-driven export of terrigenous particulate organic matter from a small mountainous river: sources, fluxes and comparisons among different rivers. Biogeochemistry 147(1):71-86. https://doi.org/10. 1007/s10533-019-00629-7

Shiah FK et al (2000) Biological and hydrographical responses to tropical cyclones (typhoons) in the continental shelf of the Taiwan Strait. Cont Shelf Res 20(15):2029-2044. https://doi.org/10.1016/s0278-4343(00) 00055-8

Shih Y-Y et al (2020) Biogeochemical variability of the upper ocean response to typhoons and storms in the Northern South China Sea. Front Mar Sci. https://doi.org/10.3389/fmars.2020.00151

Son $S$ et al (2006) Satellite observation of chlorophyll and nutrients increase induced by Typhoon Megi in the Japan/East Sea. Geophys Res Lett. https://doi.org/10.1029/2005gl025065

Sun J et al (2002) The preliminary study on phytoplankton community structure in the central Bohai sea and the Bohai strait and its adjacent area. Oceanol Limnol Sin 33(5):461-471

Sun L et al (2010) Strong enhancement of chlorophyll a concentration by a weak typhoon. Mar Ecol Prog Ser 404:39-50. https://doi.org/10.3354/ meps08477

Sun D et al (2019) Synoptic relationships to estimate phytoplankton commu nities specific to sizes and species from satellite observations in coastal waters. Opt Express 27(16):A1156-A1172. https://doi.org/10.1364/oe.27. Oa1156

Teague WJ, Jacobs GA (2000) Current observations on the development of the Yellow Sea Warm Current. J Geophys Res-Oceans 105(C2):3401-3411. https://doi.org/10.1029/1999jc900301

Trefry JH et al (1994) Transport of particulate organic carbon by the Mississippi River and its fate in the Gulf of Mexico. Estuaries 17(4):839-849. https:// doi.org/10.2307/1352752

Tsuchiya K et al (2017) Response of phytoplankton and enhanced biogeochemical activity to an episodic typhoon event in the coastal waters of Japan. Estuar Coast Shelf Sci 194:30-39. https://doi.org/10.1016/j.ecss. 2017.05.019

Wang S, Toumi R (2021) Recent migration of tropical cyclones toward coasts. Science 371(6528):514. https://doi.org/10.1126/science.abb9038

Wang Y, Wang T (2021) Numerical simulation of a heavy rainstorm in Northeast China caused by the residual vortex of Typhoon 1909 (Lekima). Atmosphere 12(1):120. https://doi.org/10.3390/atmos12010120

Wang X et al (2012) Seasonal fluxes and source variation of organic carbon transported by two major Chinese Rivers: The Yellow River and Changjiang (Yangtze) River. Glob Biogeochem Cycles. https://doi.org/10.1029/ $2011 \mathrm{gb004130}$

Wang $X$ et al (2018) Distribution characteristics and influencing factors of particulate organic carbon in the Yellow Sea and the Bohai Sea in summer of 2016. Acta Oceanol Sin 40(10):200-208

Wei Y et al (2017) Physicochemical conditions in affecting the distribution of spring phytoplankton community. Chin J Oceanol Limnol 35(6):13421361. https://doi.org/10.1007/s00343-017-6190-6

Wetz MS, Paerl HW (2008) Estuarine phytoplankton responses to hurricanes and tropical storms with different characteristics (trajectory, rainfall, winds). Estuaries Coasts 31(2):419-429. https://doi.org/10.1007/ s12237-008-9034-y

Wiegner TN et al (2012) A comparison of water quality between low- and high-flow river conditions in a Tropical Estuary, Hilo Bay, Hawaii. Estuaries Coasts 36(2):319-333. https://doi.org/10.1007/s12237-012-9576-x

Xiu S-M et al (2009) Asimulation of the seawater temperature vertical profile from satellite SST observation. Remote Sens Inform 5:73-76 
Yang H-W et al (2014) Interannual variation of the southern limit in the Yellow Sea Bottom Cold Water and its causes. J Mar Syst 139:119-127. https:// doi.org/10.1016/j.jmarsys.2014.05.007

Yu Z et al (2018) Organic and inorganic carbon and their stable isotopes in surface sediments of the Yellow River Estuary. Sci Rep 8(1):10825. https:// doi.org/10.1038/s41598-018-29200-4

Yu J et al (2019) Impacts of physical and biological processes on spatial and temporal variability of particulate organic carbon in the North Pacific Ocean during 2003-2017. Sci Rep 9(1):16493. https://doi.org/10.1038/ s41598-019-53025-4

Yu C et al (2021) Spatial-temporal characteristics of mercury and methylmercury in marine sediment under the combined influences of river input and coastal currents. Chemosphere 274:129728. https://doi.org/10.1016/j. chemosphere.2021.129728

Zhao H et al (2008) Comparison of phytoplankton blooms triggered by two typhoons with different intensities and translation speeds in the South
China Sea. Mar Ecol Prog Ser 365:57-65. https://doi.org/10.3354/meps0 7488

Zhao H et al (2013) Two phytoplankton blooms near Luzon Strait generated by lingering Typhoon Parma. J Geophys Res-Biogeosci 118(2):412-421. https://doi.org/10.1002/jgrg.20041

Zhao N et al (2019) Temporal-spatial distribution of chlorophyll-a and impacts of environmental factors in the Bohai Sea and Yellow Sea. IEEE Access 7:160947-160960. https://doi.org/10.1109/access.2019.2950833

Zheng GM, Tang D (2007) Offshore and nearshore chlorophyll increases induced by typhoon winds and subsequent terrestrial rainwater runoff. Mar Ecol Prog Ser 333:61-74. https://doi.org/10.3354/meps333061

\section{Publisher's Note}

Springer Nature remains neutral with regard to jurisdictional claims in published maps and institutional affiliations.

\section{Submit your manuscript to a SpringerOpen ${ }^{\odot}$ journal and benefit from:}

- Convenient online submission

- Rigorous peer review

- Open access: articles freely available online

- High visibility within the field

- Retaining the copyright to your article

Submit your next manuscript at $\boldsymbol{\nabla}$ springeropen.com 